\title{
SHAKESPEARE OYUNLARINDA SAHNEDE HAREKET OLUŞMASI
}

Shakespeare zamannda bugünkü anlamı ile bir "yönetmen" kavramı, yoktu. Yazarın bir görevi de, sahne arkasından oyunun akışın. yönlendirmekti. 'Shakespeare'in bağlı olduğu tiyatro bir repcrtuvar tiyatrosu idi. Hafta içinde birkaç oyu oynanırd1, oyu nlar devámi değildi, ve prova için çok az zaman kalırdı. Bu nedenle, oyuncuların konuşma, hareket, ve duruş biçimlerinin oluşması, yazar ile oyuncular arasındaki sıkı bir işbirliği ile ortaya çıkardı. Londra'ya 1613'te gelen bir Alman ziyaretçi, bu konuda şöyle der: "Ingiltere'de' oyuncular, okula gider gibi, her gün eğitiliyorlar. Baş oyuncular bile, yazarın kendilerini eğitmesini bekliyorlar."

Shakespeare, yazarın sahne dışından yönetmenlik görevini üstlenmesi ile yetinmemiştir. Oyunlarındaki șahne direktiflerine gelince. "giriş" ve "çıkış"ların dışında, hemen hemen yok denecek kadar azdır. $O$, yönetmenliği, oyundaki sözcüklere birakmıştır. Oyuncuların sahneye giriş çıkı̧̧laṛı, sahnede duruşları, verdikleri görüntü, hareket biçim ve yönleri hep sözcüklerde açılanmıştır.

Örneğin, yürüme konusunda, her oyuncunun yürüyüşü ayrı belirlenmiştir. Cressida sıradan biri gibi yürümez; çünkü Ulysses der $\mathbf{k i}$, o yürürken, "Ayakları bile konuşur/Hoppa ruhu/Bedeninin her köşesinden fişkırır" (Trolius've Cressida: IV. v. 56-7). Juliet ise Keşiş Lawrence'ın odasına girerken, yürümez, adeta uçar; çünkü sözcüklere göre, "Tüy gibi ayakları/Yere bile değmiyor" (Romeo ve Fuliet: II. v1. 16-17). Furtına'da Ariel'ın "Uçmak/Yüzmek, ateşe atlamak" (I. 11. 190--92) dizeleri onu adeta bale yapar gibi oy namaya yönlendirir. Böylece, Shakespeare sözcüklerinde bir yö netmen olarak da ölümsüzleşir.

\section{Sahneye Giriş}

Sözcüklerden yola çıkarak sahnede hareket oluşması, oyuncuların sahneye girmeleri ile başlar. Shakespeare oyunlarını, o devrin üç 
yanı açık ve seyirci ile çevrili geņ̧̣ alanlı bir sahne için yazmıştır. Oyuncu çoğunlukla sahne gerisindeki iki kapıdan birinden içeri girer, ve girer girmez de göze çarpar. Oyun alanına ulaşması için, sahnenin çapına göre, 8-10 rnetre kadar bir yol katetmesi gerekir. Shakespeare, oyuncu bu uzun mesafeyi katederken, oyunda etkili bir durum yaratır. Kral Leä'de, gözleri görmeyen yaşlı Gloucester, Edgar'ın yardımı ile sahneye girip çabalıya çabalıya öne doğru ilerlerken, Edgar ona yokuş yukarı Dover tepelerine tırmanmakta oldukları izlenimini vermeye çalışır:

Glo. Tepeye ne zaman ulaşacağım?

Edg. İste tırmanyyorsun ya. Bak ne kadar zorlanıyoruz.

Glo. Bana yer düzmüş gibi geliyor.

Edg. Yok, yok korkunç, bir yokuştayız. (IV. v1. 1-4)

Seyirci oyunda oluşan bu "aldatmaca"yı ilgi ile izlerken, bu uzun yürüyüş hem Edgar'ın amacına yardımci olur, hem de oyuncular bu arada sahneyi katẹtmiş olurlar.

Sahne önüne doğru ilerlerken geçen zamanı doldurmak için, diğer bir yönțtem de, bu arada başka oyuncuları konuşturmaktır. Venedik Taciri'nde, Bassanio jle Shylock sahne önünde. Antonio'yu beklemektedirler. Antonio'nun girişini Bassanio görür. "İ̧̧te, Senior Antonio", diye haber verirken, o yöne doğru bir baş hareketi ile, seyircinin dikkatini de yeni gelen kişiye çevirir. Antonio yanlarına yaklaşıncaya kadar, Shylock 12 dizelik bir apar söyler:

Ne kadar da dalkavuk bir meyhaneciye benziyor!

Hiristiyan olduğu için ondan nefret ediyorum.

Dahası da var,

Faizsiz ödünç para veriyor,

Venedik'te tefecilerin işine engel oluyor,

Bu yüzden de nefret ediyorum ondan. (I. 111. 42-46)

Shylock'un aparı bittiğinde, Antonio daha yolun üçte ikisini katetmiştir; Shylock Bassanio'ya dönerek, daha önce konuşmakta oldukları ödünç para verme konusuna devam eder:

Şu anda üç bin 'dukayı toplayamam.

Ama ne tasa?

Zengin dostum Tubal'dan isterim.

Altı dize sonra, Antonio yanlarina ulaşmıştır. Shylock Antonio'ya dönerek, onu oyun alanı içine çeker: "İyi günler Signior/ Biz de sizden söz ediýordụk" (60-61). 
Sahneye girecek oyuncunun nasıl gireceği 've nasıl poz alacağı, çoğu zaman, o gelmeden önce diğer oyuncuların sözlerinde belirtilir. Onikinci Gece'de, Malvolio hanımı Olivia ile evlenip evin efendisi olmayı ve etrafa duman attırmayı düşlemektedir. Kendini beğenmiş ve kendini bilmez tavirları, sahneye girmeden önce, Maria'nın sözlerinde oluşur: "Şurada, güneşin altında, yarım saattir kendi gölgcsine hava basıyor" (II.v. 15-15); sahneye girdikten sonra da takınacağı tavır Fabian'ın yorumunda yer alır:

Derin düşüncé onu ender bulunan bir erkek hindiye çevirmiş.

Baksanıza, kabarmış tüyleri ilc nasıl kurumla, caka satarak. yürüyor!

Bazen de sahnede kişinin gryabında söylenen sözlerle, sahncyc girdiği zaman sergilediği oyun arasında bir çelişki olur. Shakespcare, özellikle, komedilerinde, bu çelişkiyi hem bir ironi ögesi hem de bir eğlence ögesi olarak kullanır. Onikinci Gece'de, Sir Andrew, erkek kılığına girmiş bir genç kız olan Viola'yı kendine rakip görmektedir. Her ikisi de birbirinden habersiz, gerçekten uzak gülünç bir düelloya itilirler. Önce Viola'nın gözü korkutulur: "Bütün Illyria'da ondan daha hünerli, daha kanlı ve daha öldürücü bir adam bulunamaz" (III. 1v. 250-52). Zavallı Viola, sahneden kaçmadan önce, şöyle yanıt verir: "Onunla karşılaşmaktansa, bir rahibin peşine takılıp giderim, daha iyi. Hakkımda kim ne derse desin, umurumda değil" (255-56). Sonra, Sir Andrew Viola'ya karşı kışkırtılır: "Şeytanın ta kendisi o; daha önce onun gibi bir savaşçı hiç görmedim" (257). Sir Andrew de düellodán kaçma yanlisıdır: "Hayır, hayır, ona bulaşmak istemiyorum ... . Eğer düellodan vazgeçerse, ona en değerli atımı veririm" (263. . 69). Bu hazırlıktan sonra, sahneye geri gelen Viola korkudan tir tir titreyecek -kılicı dahil- Sir Andrew ise her an kaçmaya hazır olacaktır. Bu tavırlärı da zaten seyircinin beklentisi doğrultusundadır.

\section{Sahne Üstüinde Hareket}

Jestler

Oyuncu sahnede yapacağ jestleri, çoğunlukla, kendi sözleri ile belirler. Romeo, öldüğünü sandığı Juliet'in mezarı başında zehir 
içerek intihar edecektir; ama, Juliet'i son bir kez öpmelidir; çünkü, "Bir öpücük alıp, öyle öleceğim" der (Romeo ve fuliet: V. 111. 120).

Bazen de oyuncunun jestini bir báşka oyuncu belirtir. Lear sözleri ile iki kız kardeşin el tutuşmasını sağlar: "Ah Regan! Nasıl onun elini tutarsiz?", (Kral Lear: II. 1v. 190).

Oyuncunun yapacağ jest sembolik de olabilir. Bir K々s Masalı'nda, Hermione kocass Leontes'in arkadaşı ile sohbet ederken,. Leontes onlari uzaktan izler; ve içini bir kıskançlık bürür, "Muhabbet! Gizli niyetin, beni tam şuramdan bıçakliyor" (I. 11. 138) sözleri, eliyle göğsünü bıçaklar gibi yaptığı jestle bütünleşir.

\section{Duruş ve Görüntü}

Oyuncunun hareket biçimi, duruşu, ve vereceği görüntü de hem bir başkasının sözleri hem de kendi sözleri ile birlikte gelişebilir. Juliet Dadı'sının Romeo'dan haber getirmesini beklerken, yakını:

Yaşhlar, sanki ölii gibi,

Cansız, kurşư gibi ă̆ır ve solgun.

(Romeo ve fuliet: II. v. 16-17)

Biraz sonra Dadı, ağ́ir ağır, soluk soluğa gelecek ve bir yere çökecektir :

Yorgunluktan bittim, dur biraz soluklayalım.

Of, kemiklerim nasıl da ağrıyor.

\section{Hareket Zorlama}

Hareket gösteren sözcükler olmaksızın da, oyuncu kullandı̆̆ı başka sözcüklerle de belli bir harekete yönelir. Othello' nun karısının sadakatı konusundaki kararsızlığı, söze dökülünce, onu bir aşağı bir yukarı yürümcye zorlayacaktır:

Galiba karım dürüst, yoksa dürüst değil mi?

Sanırım sen haklisın, Iago; hayır, hayır, sen haksızsin. (Othello:- III. 111. $38 \hat{a}-7$ )

\section{Ikili Hareket}

İki oyuncunun beraber hareket edebilmeleri için, birbirlerine söylediklerine kulak vermeleri yeterlidir. Othello ve Desdemona arasındaki bir sahnede, Othello düşüncelidir; karısının kendisini Cassio 
ile aldatıp aldatmadığını çözmeye çalışmaktadır. Desdemona ise, Othello'nun, gözden düşen subayı Casio'yu affetmési için uğraşmaktadır:

Des. Sevgilim, çağır onu geriye.

Oth. Şimdi olmaz, tatl Desdemona; başka zaman.

Des. Ama, yakında mi?

Oth. Senin' için, tatlım, daha da yakında.

Des. Bu akşam yemeğinde olur mu?

Oth. Hayır, bu akşam olmaz.

Des. Öyleyse, yarın akşam yemeğinde?

Oth. Yarın akşam evde olmayacağım:

Şehirde subaylarla toplantım var.

Des. O zaman, yarın gece; veya Salı sabahı

(Othello : III. 11. 55-61)

Kar1-koca arasındaki bu soru-cevap zinciri harekete dönüştüğünde, karısının isteklerini geri çevirirken ondan kurtulmaya çalışan bir adamla, peşini bırakmayan ve sonunda onu köşeye kıstıran bir kadın görüntüsü oluşturacaktır.

\section{Sahnede Tek Bașına}

Shakespeare oỳunlarının çok belirgin bir özelliği de, "soliloqui" geleneğidir. Shakespeare oyunlarında 300 'ü aşkın solióqui kullanmı̧tır. Bu, oyuncunun sahnede tek báşına kaldığı zaman söylediği sözlerdir. Oyuncu bu durumda sahnedeki tek ilgi odağıdır. Soliloqui söylemek, oyuncunun sahnede hareketsiz kalmasinı gerektirmez. Bilakis, Shakespeare oyuncusunu, konuşurken adım adım hareketlendirir. Hareketli bir solioqui'nin en güzel örneği Cymbeline'de yer àır. Iachimo, arkadaşının genç ve güzel karısı Imogen'in yatak odasında bir sandığa saklanır. Amacı, daha sonra arkadaşına, geceyi karısı ile beraber geçirdiğ izlenemini vermektir. Iachimo'nun bu - sahnede söylediği 40 dizelik soliloqui (II. 11. 11-151), Shakespeare'in hem en uzun, hem de sözün jest ve hareketleri en çok yönlendirdiği tek kişilik bölümlerden biridir.

Iachimo gece yarısı sandıktan çıkar. "Tıpkı Romalı Tarquin'in Lucrece'ya usulca yaklaşması gibi" (11-12), sessizce uyumakta olan İmogen'in yatağına yanaşir. Genç kadın "taze bir zambak gibi"dir (15). Onun güzelliğini överken kabaran bir arzu ile, daha da yaklaşır. "Ona doku nabilirim. Belki öperim de, tek bir öpücük... . Odaya bu güzel kokuyu veren onun nefesi" (16..19). Genç kadını öper gibi 
yapar, nefesini içine çeker, ama dokunmamalıdır; çünkü, Imogen'i uyandırırsa, biraz sonra söyleyeceklerini yapamaz. Bundan sonra planını açıklar: "Odadaki herşeyi not etmeliyim" (24) derken, cebinden kağıt-kalem çıkarmak zorundadır. Iachimo odadaki eşyaları teker teker belleyip rot ederken defterine, bakışlarını, hatta bedenini onlara doğru çevirecek, belki o tarafa doğru bir iki adım bile atacaktır: Odayı iyice bellemelidir ki, sonradan arkadaşına eksiksiz anlatabilsin. Bu arada, seyirci de gözleri ile odada ayn turu atacaktır. Sira, Imogen'in kolundaki bileziği çıkarmaya gelir; onu kanıt olarak kullanacaktır: "Haydi çık! Çıksana" (33). O anda merak ve heyecan doruktadır. Ama, genç kadın uyanmayacaktır; çünkü, "Gordian'ın düğümü ne kadar sıkıysa, bilezik te o kadar kaygan"dır (34). Bileziği aldıktan sonra, Iachimo kadına iyice yaklaşmıştır; kadının geceliğinin önünü aralayıp bakacaktır; aksi halde, gördüklerini anlatabilmesi olanaksızdır:

Sol göğsünde benek benek bir ben var:

Sarı bir çiçeğin içindeki

Koyu kizil tanecikler gibi?

Imogen'in üzerine eğilirken, ọun uyumadan önce okumakta olduğu kitaba gözü ilişir. Kitabı eline alması gerekir; çünkü, Imógen'in kitapta nereye kadar geldiğini söyleyecektir (45-46). Son olarak, bir an önce sandığa geri dönmelidir, "Gecenin bekçileri/ Karanlığin gözlerini açmak üzere!" (48-9) olup, sabah çok yakındır.

\section{Seyirciye Dönük Oynamak}

Soliloqui veya apar söyleyen bir oyuncu, çoğu zaman seyirciye yaklaşarak seyirciye dönük konuşur. Bu yaklaşım hem o devrin bir geleneğidir, hem de kişinin bir gereksinimidir. Shakespeare bu yaklaşımı "emir" sözcükleri ile sağlar. Veronalı Iki Centilmen'de, Launcelot efendisi ile bir yolculuğa çıkacaktır. Yola çıkmadan önce, ailesi ile nasıl helalleştiğgini, bir soliloqui ile anlatabilmesi için, sahnenin ucuna kadar gelip, seyirciye hitap edecektir:

Bakın, büyükannem ağlaya ağlaya nerdeyse kör oldu.

Durun, size nasıl vedalaştı̆̆ımızı göstereyim. (II. 111. 11-13)

Venedik Taciri'nde, Launcelot, kendisini arayan babasını görünce, şu aparı verebilmek için gene seyirciye dönük oynamak zorundadır: "Aman Tanrım, bu gelen gerçekten benim babam... Bakın, onu şimdi nasıl ağlatacă̆ım," (II. 11. 35...51). 


\section{Sahnede Kulak Misafiri}

Shakespeare sahnesinin bir geleneği de oyuncuların birbirlerine sık sık kulak misafiri olmasıdır. Bu gelenekte oyuncuyu gerçekten gizlemeye hiç gerek yoktur. Seyirciye, "Ben saklaniyorum" demesi yeterlidir. Seyirci bu sözde-gizlenmeyi sorgusuz kabul eder. Bir Yaz Gecesi Rüyasi'nda, Oberon Demetrius ve Helena'ın konuşmalarını gizlice dinlemek için, seyirciye "görünmez" olduğunu söyler, ve sahne gerisine çekilir-artık saklanmıştır! (II. 1. 186-87).

Bir kaç kişinin ard arda birbirini gizlice dinlediği en güzel örneklerden biri Aşskn Emekleri Boşa Gitti'de yer alır. Navarre Kralı ile dostları Berowne, Longaville ve Dumain, birbirlerine kadınlardan uzak duracaklarına dair söz vermişlerdir. Ama, hepsi de aşk ateşine düşüp, sözlerini tutmamışlardır. Sırayla sahneye gelip, yalnız olduklarını sanarak, aşklarını yazıya döktükleri dizeleri gözden geçirirler (IV. 111.). Bir önce gelen, bir sonra geleni, "Bu gelen de kim?" diye haber verdikten sonra, "Şöyle bir kenara çekilip onu izleyeceğim" sözleri ile "görünmez" olur. Sadece izlemekle kalmaz, seyirciye de bir aparla açiklama yapar:

Amma da vurulmus! Devam et tatlı Cupid.

Minik okunla, ona sol taraftan, esaslı indirmişsin.

Sahneye son giren, "Ah, keşke arzu ettiğime kavuşabilsem" diye iç çektiğinde, dört bir tarafta sözde-gizlenmiş diğer oyuncular da "Ah, ben de, ben de" (90-92) diye iç çekerler. Karmaşık gibi görünen bu sahnede, oyuncular birbirlerini sözleri ile denetledikleri için, hareket düzenli bir biçimde oluşur.

\section{Sahnede Mekan Değtştirme}

Açık ve dekorsuz bir sahnede bir mekandan başka bir mekana geçilecekse, bunu sözle belirtmek gerekir. Caesar adamları ile Senato'ya gitmek üzere yoldadır. Artemidorus, "Yolun uygun bir yerinde, Caesar'ın geçmesini bekleyeceğim" sözleri ile oyunun önce "yolda" geçtiğini belirtir. Sonra Caesar'a yaklaşarak, eline bir kağıt tutuşturup, ısrarla okumasını ister. Caesar adama haddini bildirirken, aynı zamanda da, gideceği "yeri" gösterir:

Ne o, derdini sokakta mı dökeceksin?

Söyleyecek sözün varsa, Senato'ya gè. (Fulius Caesar III.

1. 11-12) 
Böyleçe aynı sahne üzerinde oyuncular bir mekandan diğerine geçmiş olurlar.

\section{Sahnede. Gruplaşma}

Shakespeare'in oyunlaiı săhneyi üç boyutlu kullanmak üzere yazılmıştır. Sahnenin geniş alanı aynı anda birkaç grubu barındırabilir. Grupların nasıl yerlerini alacakları, gene oyuncuların sözleri ile düzenlenir. Sahneye yeni gelen grup; ön sahnede oyún alanına girerken, işi biten grup geri plana geçilir. Julius Caesar'da, Cassius'un Brutus'u, Caesar'à karşı kışkırttığı uzun konuşma bitmiştir. Brutus Caesar'ın adamları ile beraber sahneye girmek üzere olduğunu haber verir. Cassius, "Önümüzden geçerlerken, Casca'yı kolundan çek/ Bize neler olduğunu anlatsın" (I. 11. 178-80) derken, hareket düzenini de çizmiş olur. Gelen katilenin Cassius ve Brutus'un önlerinden geçebilmesi için, Cassius ve Brutus ön sahneden geriye çekilmelidir. Şimdi konuşma sırası Caesar ile Antony'e geçmiştir. Caesar'ın sözleri iki grubun birbirinden uzak olduğunu gösterir:

Şurada duran Cassius'un sıska ve aç bir görünümü var;

Fazla düşünüyor: böyle adamlar tehlikelidir. (193-94)

Caesar adamları ile salkneden ayrlirken, Casca'nın dünüp, "Kolumdan çektiniz, bir şey mi söyleyecektiniz?" (213) sözleri ile Cassius ve Brutus tekrar ön sahneye gelerek oyuna girerler.

\section{Kalabalık Sahneler}

Kalabalık halk toplulu.ğunun yer aldığı sahnelerde, Shakespeare bu kalabalığın hareketini düzenlemekte büyük bir ustalık gösterir. Romeo ve fuliet, iki düşman ailenin uşaklarının, birbirlerini kavgaya kışkırtmaları ile başlar:

Samp. Kafam bozulursa, anında vururum... Montegueler'in köpeği bile beni kızdırmaya yeter.

Greg. Çek kılıcınil; işte Montegueler'den iki kişi geliyor. (I. 1. $15 \ldots 44$ )

Iki taraf birbirine girer. Benvolio uşakları ayırmaya çalışır. Ama bu kez, her an kılıcın çekmeye hazır olan Tybalt, Benvolio'yu da kavganın içine sürükler: 
$\mathrm{Ne}$ o, sen de mi bu yüreksiz ayak takımına katıldın?

Dön de ölümünle yüz yüze gel, Benvolio!

Kavga efendilere de bulaşmıştır. Bu iki ailenin sürekli kavga etmesinden usanan halk ellerinde sopalarla 'içeri girer:

Vurun, dövün şunları.

Capuletler'e Yuh! Montegueler'e Yuh!

Baba Capulet bile, "Nedir bu gürültü, verin kılıcımı" (77) diyerek ortaya atılır. Sahnede kıyasıya bir dövüş olmalıdır; çünkü, biraz. sonra içeri girecek olan şehrin prensi Escalus, herkesi ağır bir biçimde suçlayacak, ve ağır bir ceza biçecektir:

Asiler, barış düşmanları,

Kanlı ellerinizden

Atın kötüye kullandığinız silahları

Şimdi Prensinizin kararını dinleyin.

Eğer sokaklarımızın hużurunu bir kez daha bozarsanız, Bunun bedelini canınızla ödersiniz.

(83...99)

\section{Sahnede Savas}

Shakespeare Hollywood olanaklarından yoksun olduğu için, sayıșı kısıtlı olan oyuncuları ile doğal bir savaş sahnesi sergilemeye hiç girmemiştir. Onun savaşları sahne gerisindedir; sahnede ise savaştan söz edilir. Shakespeare'in 'savaşlarında çatışmadan çok konuşma vardır. Antony ve Cleopatra'da, Actium savaşı tek bir kişinin, Antony'in, izlenemleri üzerinde yoğunlaşarak anlatılır. Kısa kısa 14 sahnede savaş adım adım gelişir. Savaş haberlerini askerler sahneye getirir, Antony yorumunu yapar. Savaşa giderken Antony'in morali yüksektir:

Yarın için çok mutluyum

Zafer bekliyorum, ölüm değil.

(IV. 11. 43-44)

Savaş beklediği gibi gitmez; adamları onu terk etmeye başlarlar:

"Kötü talihim, en dürüst adamlarımın bile ahlakını bozdu" (v. 16-17). Ama, bir'sonraki çatışmada düşmanı yener. Bư zaferi coşku ile kutlayacaktır: 
Borazanlar şehrin kulaklarını çınlatsın,

Yer gök birbirine seslensin,

Gelişimizi alkışlașın.

(v111. 36...40)

$\mathrm{Bu}$ kısa bir zafer sarhoşlığudur. Antony yanlış bị savaş taktiği sonucu yenik düşer:

Her şeyi yitirdim

Ey güneş, doğuşunu bir daha hiç görmeyeceğim.

(x11. $9 \ldots 19)$

Bu yenilgiyi canı ile ödeyecektir: "Kendi sonumu kendim getireceğim" (xıv. 21-22). Böylece, inişli-çıkışli girift bir savaş, sözcüklerin yarattığı imgelerle, sernbolik olarạk hareketlenmiş olur.

\section{Sahneden Çıkış}

Shakespeare sahnesinde kapanan bir perde, kararan bir 1şık, çarplacak bir kapı, veya arkası.na geçilecek bir yan bölme yoktur. Oyuncu sahneden çıkmak için sahne gerisine gidinceye kadar, bir süre daha seyircinin gözü önündedir. Bu nedenle, hem seyirciyi bu çıkışa hazırlaması, hem de sahneden etkili bir biçimde çıkması gerekir. Coriolanus vatandaşları tarafından Roma'dan sürülmüştür. Sahneden ayrulmadan önce, Romalılar'a karşı nefret, öfke ve aşağılama dolu bir konuşma yapar:

\section{Ben sizi sürüyorum}

Aşağılık şehrinize, işte böyle arkamı dönüyorum,

Başka bir yerde, başka bir dünya bulmak için. (Çıkar)

(Coriolanus III. 111. 123-135)

Bu sözlerden. sonra, sahneden sürgüne giden biri gibi değil, gururlu, ama öfke ve kinden kủdurmuş biri olarak çıkacaktır.

Bazen oyuncu sahnedent konuşmadan ayrılır; ama, nasıl çıkacağı, bir başka oyuncu nun sözleri ile anlatılır. Hamlet'teki Hayalet sahneden öylesine yürüyüp çıkmaz; Marcello ve Bernardo'nun söylediğ́ine göre, "Kızgın/ Başı dik ve gurur!u" (I. 1. 53-54), Horatio' nun anlattığına göre de, "Horoz sesini duyar duymaz/ Alelacele toparlanı" (I. 1. 218-19) ayrilir sahneden. 
Sahneden bir grup ayrılacağı zaman, çıkmak üzere olduklarıní aralarında konuşarak, seyirciyi hazırlarlar. Bir Taz Gecesi Rüyası'nda, Quince ve arkadaşları, sarayda oynayacakları oyunun ilk provasını bitirmişlerdir. Bir sonraki provayı kararlaştırırken, sahneden çıkış hazırlığına, da başlamış olurlar:

Quince. Beyler, işte rolleriniz, yalvarırım, lütfen, rica ediyorum, yarın akşama kadar ezberleyin. Yarın akşam ay ışı̆̆ında, şehrin dişındaki ormanda buluşalım. Provamızı orda yapacağız... lütfen beni yaya birakmayin.

Bottom. Yarın buluşacağız; canla başla prova yapacağız; çok sıkı çalışacağız. Haydi hoşça kalın.

Quince. Yarın, ormanda, unutmayin.

Bottom. Tamam! Sözünden dönen ne olsun! (Çıkarlar) (I. 11. $97 \ldots 110)$

\section{Son Söz}

Sonuç olarak, bir Shakespeare oyunu hareketlendirmek için, kişilerin söylediklerine kulak vermeliyiz. Yönetmen Shakespeare sözcükleri ile, bize her an yardıma hazırdır. Bir Shakespeare oyunu sahnede görmek, yönetmek, veya oynamak fursatı kolay kolay elimize geçmeyebilir. Ama, iç dünyamızdaki sahnedé, sözcüklerin yardımı ile, her birimiz birer yönetmen veya oyuncu olabiliriz.

\section{Kaynakça}

Shakespeare, William. 1977. Antony ve Cleopatra. The New Penguin Shakespeare.

1982. Aş̧ıın Emekleri Boşa Gitti. The New Penguin Shakespeare.

1971. Bir Yaz Gecesi Rüyasi. The Macmillan Shakespeare.

1977. Coriolanus. The New Penguin Shakespeare.

1988. Cymbeline. The Arden Shakespeare.

1974. Firtına. The New Penguin Shakespeare. 
1987. Hamlet. The Arden Shakespeare.

1979. Julius Caesar. The New Penguin Shakespeare. 1983. Onikinci Gece. The Pelican Shakespeare. 1978. Othello. The New Penguin Shakespeare. 1981. Romeo ve Fuliet. The New Penguin Shakespeare. 1980. Trolius ve Cressida. The Pelican Shakespeare. 1968, Veronall iki Gentilmen. The New Penguin Shakespeare. 